\title{
The Founder of Zoom Shares What's Next
}

\author{
Eapen Chacko (Queblo, Inc. )
}

KEYWORDS: Information Technology, COVID-19.

Zoom Video Communications, Inc., the online videoconferencing service, is everywhere now, as the COVID-19 pandemic shuts down businesses, schools and organizations. Zoom's revenue, which nearly doubled in the fiscal year ending January 31, 2020 from the previous year, is expected to grow even more as usage increases by $1,900 \%$ around the world. (https://blog.zoom.us/wordpress/2020/04/01/a-messageto-our-users/)

Today, in the second quarter of 2020 , the name Zoom is ubiquitous. This is especially so in healthcare, where it is a powerful tool for collaboration among disparate types of professionals in non-office settings of all kinds, from the cardiac catheterization lab to ICUs to homes where hospital staff are working remotely.

The founder of Zoom, Eric Yuan, spoke on April 1 at a Global Summit hosted by GSV (Global Silicon Valley), a modern merchant bank focusing on technology and digital learning. While these summits are traditionally held in San Francisco, this one was live-streamed. Cohosted by Arizona State University, the summit attracted tech founders and executives, students, investors, analysts, investment bankers and public leaders to discuss important issues.

Yuan began his career with Webex, where he was one of four founding engineers. Webex, in his words, was an early version of an application trying to deliver videoconferencing over the Web. Soon, tech giant Cisco Systems acquired Webex and sold its equipment as part of expensive, customized, voice and video packages sold by third parties. Post-acquisition, Yuan became a Vice President of Engineering at Cisco, working for the Cisco Webex venture, until about 2007. In 2011, he founded Zoom.

Conference co-founder Michael Moe -- a former colleague of mine at Dain Bosworth in Minneapolis -spoke with Yuan about his company's new prominence, about its origins and growth, and about what comes next. Here are some highlights and takeaways from that talk.

\section{The Market Will Tell You What's Needed, If You Listen}

While working for both the stand-alone Webex and Cisco Webex[1] (https://www.webex.com/), one of Eric's jobs as a sales engineer was to listen to customers. Great inventors, entrepreneurs, investors, analysts, medical diagnosticians and others are good observers, who often listen more than they speak, but also are gregarious with people. From Eric's projection on the video, I am sure that his customers loved him, and they likely felt that he would faithfully represent their interests to his senior management.

"I suddenly realized that all my customers were unhappy about something!," Yuan recalled. He wondered how this could be. He also probably realized that it was unlikely that the multibillion-dollar Cisco would invest in reinventing a small product for which it had just paid handsomely. So, Zoom was born in 2011.

This need to listen to customers was also discussed at some length in "Things a Little Bird Told Me," the 2014 book by Twitter co-founder Biz Stone, whose duties included answering texts and IM's from his always-on customers about what they liked and didn't like, and what new features they'd love to see.

Yuan's feedback from Webex customers is what led to the founding of Zoom, so it is a timeless lesson with a current example. Nine years after its founding in 2011, Zoom did its initial public offering ("IPO") on April 23,2019.

\section{Fortune Favors the Prepared}

For the year ended January 31, even before the pandemic caused a rush for its services, Zoom recorded exceptional growth and a profit (https://investors.zoom.us/staticfiles/09a01665-5f33-4007-8e90-de02219886aa) . It reported revenue of $\$ 622.7$ million, compared to $\$ 330.5$ 
million in the prior-year period, an increase of $88.4 \%$ year-over-year. It also reported a net profit, according to generally accepted accounting principles not "adjusted" income, of $\$ 25.3$ million, compared to $\$ 7.6$ million in the prior-year period, an increase of $233 \%$. The company has cash on the balance sheet, and little debt except for leases.

A founder could certainly pat himself on the back for the hard work of 11 years paying off handsomely. But right on the heels of its healthy fiscal year returns, Covid-19 and the unknown risks it causes to things from personnel to supply chains has created new opportunities for even more growth. This opportunity could not have come if Yuan had not listened to his Webex customers and if Zoom had not been so welldesigned. Zoom's video streaming features and ease of use, a key design requirement, made it ripe for adoption by the millions forced to work remotely. As Yuan said in his presentation: "It just works."

\section{Video is the new voice}

Before the onset of Covid-19, and during the robust growth of the past fiscal year, daily meetings numbered in the "hundreds of thousands," but today they are "in the millions," Yuan said. The growth has come despite Zoom's limited sale focus. For the past nine years its corporate sales process had focused on the biggest customers and secondarily, on healthcare systems -which are not tech savvy, have lots of disconnected systems and are slow to change.

Now, because of the need for quick, reliable and secure face-to-face video communication, universities, schools, municipalities, law enforcement and governments among others are all calling to deploy Zoom throughout their organizations.

\section{Good leaders look around the corner}

Even as Eric Yuan speaks in English, one feels that his thinking is coming from his native China when he says things like, "Zoom delivers happiness and fundamentally changes the way people interact." $\mathrm{He}$ believes it fosters more empathy and trust.

What is his biggest worry? Not the next quarter's results, partly because Covid-19 will have all companies reporting subpar or bad results. Like most CEOs, Yuan is worried about online security and privacy of individual's identities and sensitive information. In healthcare settings, for example, much more patient health information is being shared, which could cause HIPAA compliance problems.

"For the next six months, I think that I will be Chief Security Officer," Yuan notes. He was looking around the corner at what success was potentially exposing right now. Good leaders don't rest on their laurels, and every entrepreneur needs to remember this.

Zoom is not the only videoconferencing product today, and someday its suppliers, like Amazon Web Services and Microsoft Azure Cloud Services, might even become competitors. But it's always instructive and educational to see a good leader speak, even in video! 